\title{
Extensive Subamniotic Haematoma
}

\author{
António Gonçalo Inocêncio Vila Verde, Lúcia Fabiana Silva Coutinho, Fernanda \\ Pacheco and Rosa Zulmira Vaz Macedo
}

Department of Obstetrics and Gynecology, Centro Hospitalar do Porto, Maternidade Júlio Dinis, Porto, Portugal

Correspondence should be addressed to: Gonçalo Inocêncio; inocencio@portugalmail.com

Received date: 10 January 2014; Accepted date: 12 March 2014 ; Published date: 13 june 2014

Academic Editor: Svein A. Rasmussen

Copyright (C 2014. António Gonçalo Inocêncio Vila Verde, Lúcia Fabiana Silva Coutinho, Fernanda Pacheco and Rosa Zulmira Vaz Macedo. Distributed under Creative Commons CC-BY 3.0

\begin{abstract}
Cases of extensive placental haematomas that persist beyond the second trimester until the end of pregnancy are extremely rare and are associated with poor obstetric outcome. We describe a case of a massive subamniotic haematoma diagnosed by ultrasound in the first trimester, confirmed by magnetic resonance imaging that persisted till the end of pregnancy. Despite the large size of the haematoma, complications such as placental abruption or fetal growth restriction did not occur, and pregnancy had a favourable outcome. On pathological examination, more than $50 \%$ of the placenta showed signs of an extensive organized subamniotic haematoma.
\end{abstract}

Keywords: Extensive placental haematoma; Magnetic Resonance Imaging; pregnancy; subamniotic haematoma; ultrasound imaging

\section{Introduction}

During pregnancy, according to Trop and Levine (2001), we can distinguish three types of placental haematomas, depending on their location:

Subchorionic haematomas are between the chorion and endometrium;

Retroplacental haematomas are entirely behind the placenta and not touching the gestational sac;

Subamniotic or preplacental

haematomas are contained within amnion and chorion.
Of the three different types of placental haematomas, subamniotic haematoma is considered the rarest.

Although small placental haematomas are usually asymptomatic, Hodgson et al (2007) mentioned that they can originate vaginal bleeding, abdominal pain, premature labour and threatened abortion.

The majority of placental haematomas spontaneously regress by the end of the second trimester, but some may persist until the end of pregnancy. Seki et al (1998) suggested that these persistent 
haematomas have the potential to cause problems or complications for the mother or fetus.

\section{Case}

Healthy woman, 34 year-old, gravida 4 para 1 (two $1^{\text {st }}$ trimester spontaneous miscarriages and one term birth by caesarean section 7 years ago).

In the $1^{\text {st }}$ trimester ultrasound scan, at 12 weeks gestation, it was observed a hypoechogenic image, indissociable from the placenta, with $49 \mathrm{~mm}$ of diameter - see figure 1.

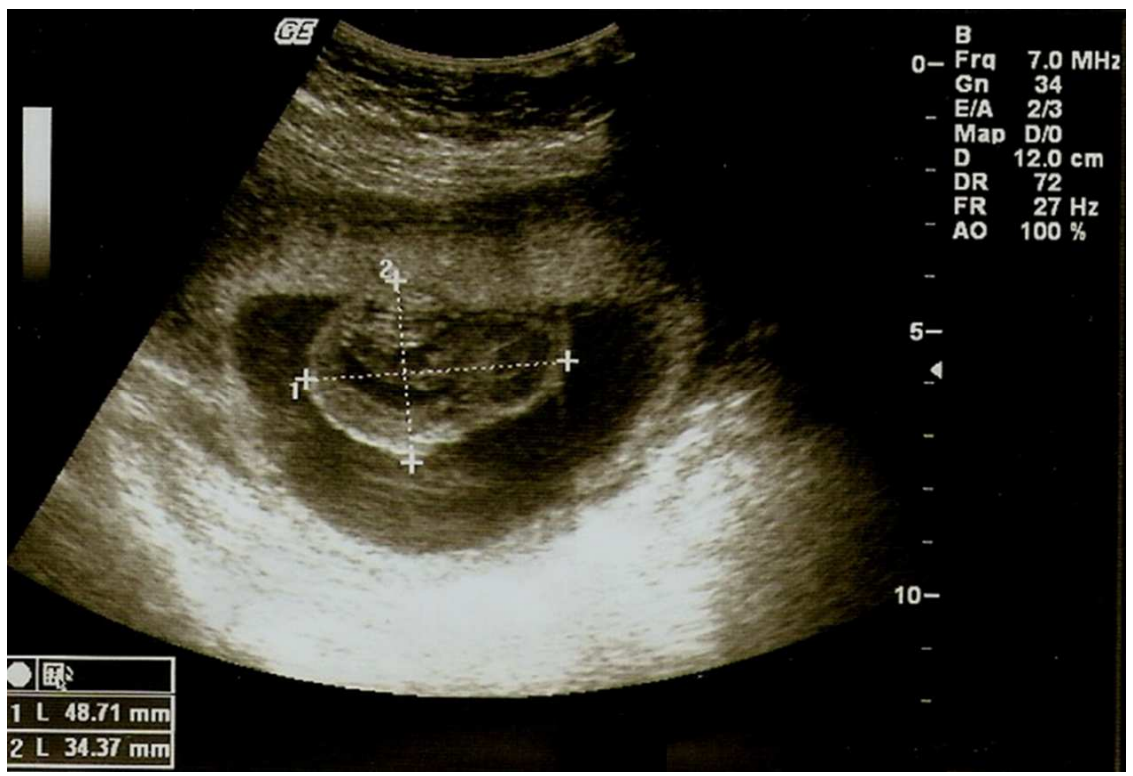

Figure 1: Subamniotic haematoma, at 12 weeks gestation, by ultrasound scan

Colour Doppler showed no blood flow. The umbilical cord showed no abnormalities, with 3 vessels and central insertion in placenta.

The patient denied any vaginal hematic loss since she became pregnant. Physical and gynaecological examination was normal.

At 20 weeks of gestation, the image has enlarged to approximately $100 \mathrm{~mm}$ in diameter, keeping the same echogenic features. We decided to submit the patient to a Magnetic Resonance Imaging (MRI).

The MRI, performed at 21 weeks gestation, confirmed the presence of an expanding lesion within the gestational sac, occupying the upper right quadrant, measuring 120x107x80mm.

Its characteristics were highly suggestive of a haemorrhagic lesion, attributable to an old haemorrhage. Its imaging features did not suggest the diagnosis of gestational trophoblastic disease. No changes were observed in the fetal or umbilical cord blood. The amniotic fluid volume was normal for the gestational age.

The pregnant woman underwent ultrasound scan every 3 or 4 weeks. The image remained stable and fetal growth and amniotic fluid volume were normal. The rest of pregnancy was uneventful without any complaints or vaginal hematic loss.

It was decided to perform an elective caesarean section at 37 weeks gestation that resulted in a female newborn, weighing 2770gr, Apgar score 8 in the first minute and 10 in the fifth minute of life. Over $50 \%$ of the placenta showed signs of an extensive organized subamniotic haematoma, with approximately $12 \mathrm{~cm}$ in diameter, confirmed by pathological examination - see figures 2 and 3. 


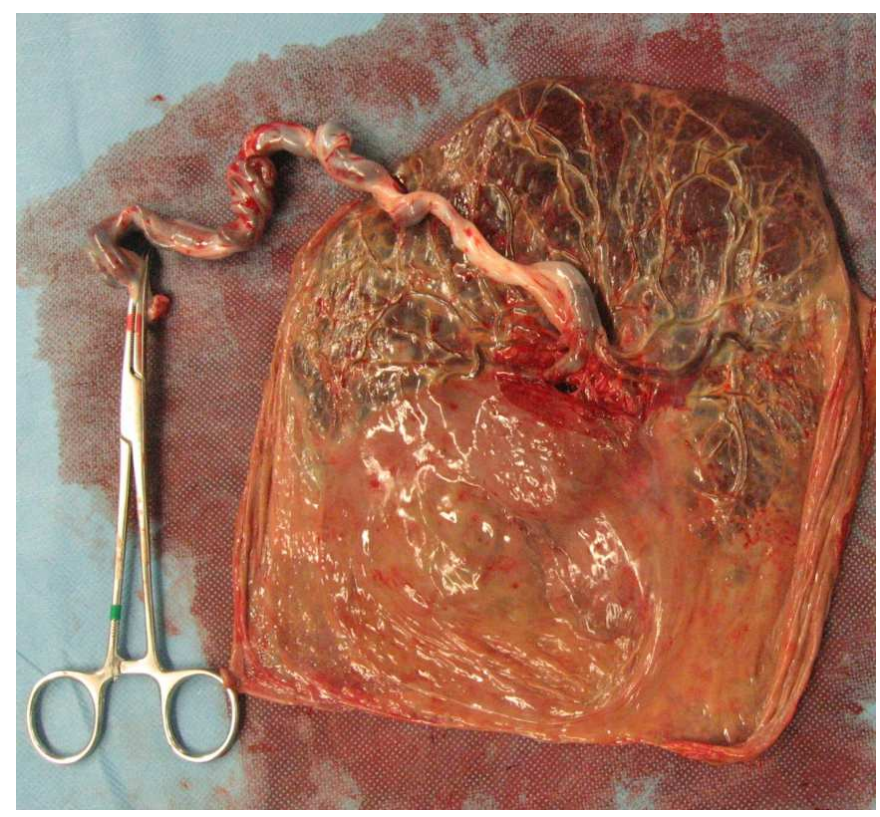

Figure 2: Extensive subamniotic haematoma

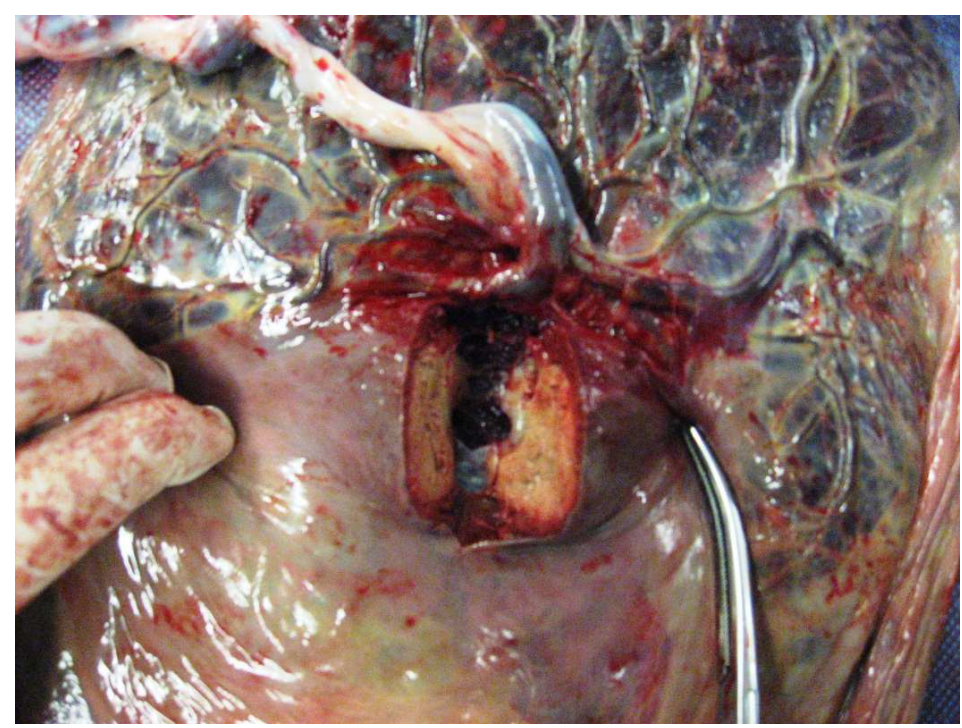

\section{Figure 3: Amnion opening with visualization of the organized haematoma}

\section{Comment}

According to Deans and Jauniaux (1998), subamniotic haematoma is an extremely rare condition that should always be considered as a pathological lesion, since it can cause obstetric complications, namely fetal growth restriction.
For differential diagnosis we thought of the following sceneries: placental haematoma? Aberrant cotyledon? Gestational trophoblastic disease (partial mole)? Chorioangioma? Submucosal fibroid? We have excluded aberrant cotyledon and submucosal fibroid, namely because tumefaction location was between the chorion and the amnion. Gestational trophoblastic disease was improbable 
because of the imaging features of the tumefaction (the characteristic vesicular swelling of chorionic villi was not observed). As there were no abnormalities observed in the umbilical cord, in particular in its placental insertion portion, and as there was no blood flow in colour Doppler imaging the diagnosis of chorioangioma was unlikely.

As Kojima et al (2001) stated that ultrasound alone may not be sufficient to definitely exclude the differential diagnoses of placental haematoma, we decided to perform magnetic resonance imaging in an attempt to better characterize the tumefaction.

Apart from sexual intercourse abstinence and avoiding heavy lifting and efforts, we just kept close clinical and ultrasound surveillance.

As in our case, the pregnant woman had previous history of caesarean section, Bishop Score was less than 2 at 37 weeks gestation and as women with subamniotic haematomas are at increased risk of obstetric complications, we opted for an elective caesarean section at 37 weeks.

\section{Conclusion}

In conclusion, even extensive subamniotic haematomas, as presented in this case, can have favourable obstetric outcome.

\section{References}

1. Deans A, Jauniaux E. (1998) 'Prenatal diagnosis and outcome of subamniotic hematomas,' Ultrasound Obstet Gynecol, 11(5):319-23.

2. Hodgson DT, Lotfipour S, Fox JC. (2007) 'Vaginal bleeding before 20 weeks gestation due to placental abruption leading to disseminated intravascular coagulation and fetal loss after appearing to satisfy criteria for routine threatened abortion: a case report and brief review of the literature,' J Emerg Med; 32(4):387-92.

3. Kojima K, Suzuki Y, Makino A, et al. (2001) 'Case of Massive Subchorionic Thrombohematoma Diagnosed by Ultrasonography and Magnetic Resonance Imaging,' Fetal Diagn Ther; 16:57-60.

4. Seki H, Kuromaki K, Takeda S, et al. (1998) 'Persistent subchorionic hematoma with clinical symptoms until delivery,' Int J Obstet Gynecol; 63:123-8.

5. Trop I, Levine D. (2001) 'Hemorrhage During Pregnancy: Sonography and MR Imaging,' Amer Journal Roentgenology; 176:607-615. 